\title{
Site-Specific Septoria Leaf Blotch Risk Assessment in Winter Wheat Using Weather-Radar Rainfall Estimates
}

\author{
A. Mahtour and M. El Jarroudi, Université de Liège, B-6700 Arlon, Belgium; L. Delobbe, Royal Meteorological Institute, B-1180 \\ Brussels; L. Hoffmann, Centre de Recherche Public-Gabriel Lippmann, Département Environnement et Agro-biotechnologies, L-4422 \\ Belvaux, Grand-Duchy of Luxembourg; H. Maraite, Earth \& Life Institute, Université catholique de Louvain (UCL), B-1348 Louvain- \\ la-Neuve, Belgium; and B. Tychon, Université de Liège, Arlon, Belgium
}

\begin{abstract}
Mahtour, A., El Jarroudi, M., Delobbe, L., Hoffmann, L., Maraite, H., and Tychon, B. 2011. Site-specific Septoria leaf blotch risk assessment in winter wheat using weather-radar rainfall estimates. Plant Dis. 95:384-393.

The Septoria leaf blotch prediction model PROCULTURE was used to assess the impact on simulated infection rates when using rainfall estimated by radar instead of rain gauge measurements. When comparing infection events simulated by PROCULTURE using radar- and gaugederived data, the simulated probability of detection (POD) of infection events was high ( 0.83 on average), and the simulated false alarm ratio (FAR) of infection events was not negligible ( 0.24 on average). For most stations, simulation-observed FAR decreased to 0 and simulationobserved POD increased ( 0.85 on average) when the model outputs for

both datasets were compared against visual observations of disease symptoms. An analysis of 148 infection events over 3 years at four locations showed no significant difference in the number of infection events of simulations using either dataset, indicating that, for a given location, radar estimates were as reliable as rain gauges for predicting infection events. Radar also provided better estimates of rainfall occurrence over a continuous space than weather station networks. The high spatial resolution provides radar with an important advantage that could significantly improve existing warning systems.
\end{abstract}

Septoria leaf blotch (SLB) of wheat (Triticum aestivum), caused by Mycosphaerella graminicola (anamorph Septoria tritici), is an important disease in many parts of the world $(20,33)$. It can cause considerable yield loss if the flag and second leaves $(35,37)$ are severely affected before the grain-filling stage. In Belgium and the Grand Duchy of Luxembourg, this disease regularly reduces yield by up to $30 \%$ (9). Nevertheless, SLB development on the upper leaves is inconsistent between years and fields. Early infection of the upper leaves generally requires rain-splash dispersal of the conidia produced on the lower leaves to the upper ones during the stem-elongation phase. Delayed establishment of infection on the lower leaves, absence of rain, or prevalence of conditions unfavorable for infection during the stem-elongation phase increases the distance between the healthy and infected leaves and, therefore, hampers disease progress to the upper layers. The lengthy and variable incubation period (17 to more than 30 days, depending on the temperature) also needs to be considered (34). The irregularity of SLB development in Western Europe and the difficulty of SLB risk assessment for farmers has resulted in prophylactic fungicide applications at two or three growth stages, although trials often demonstrate cost effectiveness for only one or even no fungicide application. Environmental concerns and changes in the cost/price ratio in wheat production have also increased the demand for site-specific SLB risk assessment and fungicide application decision-support systems.

Since the early $1990 \mathrm{~s}$, various forecasting models have been used to support decisions for plant disease management by simulating the relationship between meteorological data and SLB infec-

Corresponding authors: A. Mahtour and M. El Jarroudi,

E-mail: amahtour@doct.ulg.ac.be and meljarroudi@ulg.ac.be

Accepted for publication 15 December 2010.

doi:10.1094/PDIS-07-10-0482

(C) 2011 The American Phytopathological Society tion periods $(1,12,15,17,31-33,39)$. One of them, PROCULTURE, applied mainly in Belgium and Luxembourg, is an interactive Webbased, field-specific, decision-support system based on the mechanistic modeling of the development of the last five leaf layers of the crop and of SLB development on these layers $(10,26,29,30)$. The inputs are (i) temperature, relative air humidity, and rainfall data provided by a network of automatic weather stations; (ii) fieldspecific data such as location, sowing date, and cultivar susceptibility; and (iii) one adjustment around the first node of the actual growth stage and of SLB incidence on one particular leaf layer specified by the model. The model considers infection to have occurred when, during a 2-h rainfall event, precipitation for the first hour is at least $0.1 \mathrm{~mm}$, to allow for the swelling of pycnidia, followed by a second hour with at least $0.5 \mathrm{~mm}$ of precipitation, leading to the release and splash dispersal of the conidia $(3,10,26)$. In addition, after rainfall, relative humidity should be higher than $60 \%$ during the following $16 \mathrm{~h}(10,26)$ and the temperature should remain above $4^{\circ} \mathrm{C}$ for $24 \mathrm{~h}(3,10)$ for germination and infection.

The assessment of the PROCULTURE model at several sites in Belgium (29,30) and Luxembourg (10) showed that the model can explain disease progression in the canopy and can be used to advise farmers when to apply fungicides during stem elongation, when the three upper leaves emerge (10). Overall, the assessment of the infection periods achieved an accuracy of $85 \%$. Overestimation or underestimation of the risk could often be traced back to differences in rain events captured by the tipping-bucket rain gauges at the weather station compared with the rainfall to which a particular field was actually exposed. Rainfall data could be interpolated between weather stations but precipitation between fields is characterized by high spatial and temporal variability $(18,25)$, making the interpolation unreliable $(16,19)$.

Radar may provide a solution for improving the interpolation of precipitation $(41,42)$. Over the past few years, radar-derived estimates have been increasingly used in disease forecasting applications as an alternative to gauge-derived measurements $(5,41)$. Weather-radar imagery that provides a continuous spatial assess- 
ment of rainfall at frequent time steps $(<1 \mathrm{~h})$ may assist in the interpolation of rainfall events. In comparison with weather station networks, radar is advantageous in measuring rainfall everywhere in the area covered by the instrument, which is not the case with the networks that limit their rainfall measurements to within 400 $\mathrm{cm}^{2}$ of the rain gauges included in the network.

Since November 2001, the Royal Meteorological Institute of Belgium (RMI) has been operating a new Gematronik C-band Doppler weather-radar system in southern Belgium, near the borders with France and Luxembourg. This is the first weather radar covering the whole of Luxembourg and southern Belgium. The RMI weather radar carries out a standard scan of the atmosphere every $5 \mathrm{~min}$, with 5 -min elevation angles $(0.3,0.9,1.8,3.3$, and $6^{\circ}$ ). It allows precipitation events to be detected within a maximum range of $240 \mathrm{~km}$. More detailed information on the RMI weather radar is given elsewhere $(2,7,13)$.

Getting an accurate rainfall assessment at a high spatial resolution is essential for the accurate forecasting and management of SLB and other plant diseases. The objective of this research was to assess the feasibility of using radar-estimated rainfall data to improve the forecasting of SLB on winter wheat in Belgium and Luxembourg. RMI weather-radar performance was evaluated by comparing hourly rainfall estimates with actual rain-gauge measurements to evaluate the precision, accuracy, and limitations of radar data for agrometeorological applications linked to plant disease assessment. The infection events simulated by PROCULTURE $(10,29,30)$ using, as input rainfall data, both rain-gauge measurements and radar assessments, were also quantified. These two sets of simulated infection periods were then compared with infection periods deduced from visually observed symptoms.

\section{Materials and Methods}

Disease assessment. Replicated field experiments were established in three villages in Luxembourg (Diekirch district, Reuler $\left[50^{\circ} 11^{\prime} \mathrm{N}, 5^{\circ} 15^{\prime} \mathrm{E}\right]$; Grevenmacher district, Burmerange $\left[50^{\circ} 3^{\prime} \mathrm{N}\right.$, $\left.6^{\circ} 1^{\prime} \mathrm{E}\right]$; and Luxembourg District, Useldange [49 $\left.29^{\prime} \mathrm{N}, 6^{\circ} 19^{\prime} \mathrm{E}\right]$ ) and in one village in Belgium (Humain [ $\left.49^{\circ} 46^{\prime} \mathrm{N}, 5^{\circ} 58^{\prime} \mathrm{E}\right]$ ), during the growing seasons in 2003, 2004, and 2005 (Table 1). Experimental fields were typically sown in approximately mid-October. The sowing and harvest methods and crop practices used reflected the usual wheat production practices in Belgium and Luxembourg. At each location and for each growing season, susceptible wheat cultivars were sown in a randomized block design with four replicates. The plant growth stages (GSs) were assessed according to the decimal Zadoks scale (43). All plots received $\mathrm{N}$ at 40 to $70 \mathrm{~kg} / \mathrm{ha}$ in the form of ammonium nitrate at GS 25 (main shoot and five tillers), followed by $\mathrm{N}$ at 60 to $70 \mathrm{~kg} / \mathrm{ha}$ at GS 32 (second node detectable), and a final application of $\mathrm{N}$ at 65 to 95 $\mathrm{kg} / \mathrm{ha}$ at GS 59 (emergence of inflorescence completed). Weeds were controlled by one application of a preemergence herbicide (IP FLO, 1.0 liter/ha, containing isoproturon at $500 \mathrm{~g} / \mathrm{liter}$; Cheminova Agro, Senlis, France) and one post-emergence herbicide (Javelin, 2.0 liters/ha, containing diflufenican at $62.5 \mathrm{~g} /$ liter and isoproturon at $500 \mathrm{~g} /$ liter; Bayer CropScience, Monheim am Rhein, Germany). No fungicides were applied over the entire trial area.

Because the top three leaves account for most of the wheat yield $(27,35,37)$, disease development was considered only on these leaves (starting from the flag leaf: L1, L2, and L3). Disease severity was monitored weekly for 10 stems per plot of 8.0 by $1.5 \mathrm{~m} \mathrm{(40}$ plants in total per cultivar and per site). Assessments were made from April to July, with a final observation at GS 73 to 77 (milk development) (43). Standard leaf area keys for SLB were available to the evaluators who assessed the percentage of infection in the fields (21), and training software programs for assessing disease severity, such as DISTRAIN (38), were used to teach evaluators about disease assessment prior to the experiment.

Comparison of radar and gauge rainfall data. The quality of radar data was assessed through a comparison with 77 tipping-bucket rain gauges from the Hydrological Service of the Walloon Region of Belgium (SETHY). Data quality control was ensured by both RMI and SETHY. The SETHY rain-gauge network was selected because of its reliability and its previous use in a similar study (2).

Radar measurements collected every $5 \mathrm{~min}$ were summed hourly. The hourly weather-radar data were extracted from radar images averaged over nine radar pixels (i.e., an area of $1.8 \mathrm{~km}^{2}$ with the pixel points centered over the positions of the rain-gauge stations; radar pixel size was 600 by $600 \mathrm{~m}^{2}$ ). The weather-radar precipitation estimates were calculated in line with the standard relationship described by Marshall and Palmer (28). The raw radar reflectivity $(Z)(41,42)$ was converted into rainfall depth $(R)$ using a reflectivity-precipitation rate $\left(Z=200 \mathrm{R}^{1.6}\right)$ relationship (8).

The comparison between radar- and gauge-derived data was made from March to July over 3 years (2003, 2004, and 2005). In total, approximately 270,000 data points were processed annually. This period was chosen because it corresponded to the most important part of the crop growing season and the life cycle of the pathogen (10). For this comparison, an analysis of rainfall amounts and occurrences was conducted for each station by comparing hourly rainfall events estimated by the RMI radar with precipitation measured by the rain gauges. For rainfall amounts, data were cumulated per month. For each radar $(R)$-gauge $(G)$ data pair, an $R / G$ ratio was calculated as a mean value over all stations. With regard to the radar's ability to determine the presence or absence of precipitation, a dichotomous categorical verification was performed to quantify the proportion of hourly events correctly estimated by the weather radar (40). Various terms were used for the comparison, including the probability of detection (POD), false alarm ratio (FAR), and critical success index (CSI) $(6,40)$. These statistical scores were calculated using the following formulae:

$\mathrm{POD}=a /(a+c) ; \mathrm{FAR}=b /(a+b) ; \mathrm{CSI}=a /(a+b+c)$

where $a=$ precipitation, measured by a rain gauge and detected by radar; $b=$ precipitation detected by radar but not measured by a rain gauge; and $c=$ precipitation measured by a rain gauge but not detected by radar. The values for the three scores ranged from 0 to 1. A perfect score for both POD and CSI was 1 . In contrast, a value of 0 was the best possible score for FAR. In order to overcome the problem of extremely low rainfall amounts $(\leq 0.1 \mathrm{~mm})$ caused by the detection limits of both instruments, adjusted POD, FAR, and CSI (POD', FAR', and CSI', respectively) were also calculated. In this case, rainfall occurrence was assumed when rainfall threshold was $>0.1 \mathrm{~mm}$.

Finally, in order to identify the source of errors, contingency tables for hourly precipitation occurrence were constructed for both radar and gauge data, with categories of 0 to $0.1,0.1$ to $0.2,0.2$ to $0.3,0.3$ to $0.4,0.4$ to $0.5,0.5$ to 1,1 to 2 , and $>2 \mathrm{~mm}$.

Impact of radar-derived rainfall data on the accuracy of SLB forecasting. The incidence of infection estimated by the

Table 1. Location of the four winter wheat trials during the cropping seasons in 2003, 2004, and 2005

\begin{tabular}{lll}
\hline Site, distance $(\mathbf{m})^{\mathbf{a}}$ & Year & Cultivar \\
\hline Humain & & \\
10 & 2003 & Centenaire \\
50 & 2004 & Drifter \\
50 & 2005 & Drifter \\
Useldange & & \\
500 & 2003 & Achat \\
& 2004 & Achat \\
Burmerange & 2005 & Achat \\
500 & & \\
200 & 2003 & Dekan \\
500 & 2004 & Cubus \\
Reuler & 2005 & Cubus \\
500 & & \\
50 & 2003 & Bussard \\
10 & 2004 & Bussard \\
\hline
\end{tabular}

${ }^{a}$ Field sites and distance to weather station; the Humain site is in Belgium and the Useldange, Burmerange, and Reuler sites are in Luxembourg. 
PROCULTURE model, with two rainfall input datasets (i.e., 14 rain-gauge measurements and the RMI weather-radar estimates) were assessed. The 14 rain-gauge stations belonged to four individual networks. Three of these stations were part of the RMI network, seven were from the Promotion of Agrometeorology in Southeastern Belgium network, three were Administration des Services Techniques de l'Agriculture stations, and one was a CRPGabriel Lippmann station in Luxembourg (Fig. 1). These meteorological stations were included because they provided hourly data on relative humidity, temperature, and rainfall that were necessary for PROCULTURE.

The effect of rainfall data source, from either rain gauges or radar, was also assessed by a comparison between field observations of SLB severity (the reference) and model results including both rainfall estimates in four selected weather stations near the four

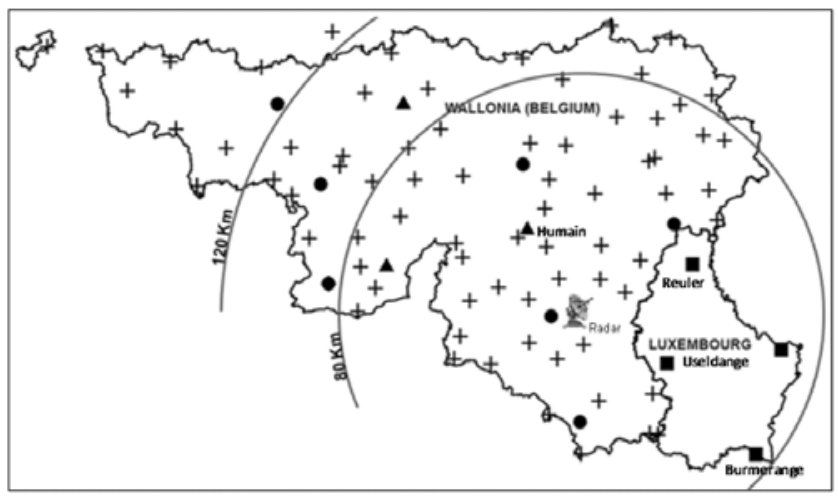

Fig. 1. Location of the weather radar of the Royal Meteorological Institute (RMI) of Belgium, the 77 automatic stations of the Hydrological Service of the Walloon Region of Belgium (+), the seven agrometeorological stations of the Promotion of Agrometeorology in southeastern Belgium ( ), the four automatic stations in Luxembourg (घ), and the three automatic stations of the RMI $(\boldsymbol{\Delta})$. The circles represent the range of the weather radar. field trials. The identification of infection events was based on the development of symptom severity over time. An infection event was considered to have occurred when disease severity increased significantly between two successive observations. A comparison $(t$ test) with a threshold of $\alpha=0.05$ was performed on these consecutive field observation values to verify the significance of the increment (10). Thus, when the severity level was low (0 to $15 \%$ ), a new infection was assumed if the lesions increased by more than $1 \%$ between two observations. When the severity level was higher than 15 to $20 \%$, the increase had to be higher than $10 \%$ to be significant (29). This was because the increase in disease severity was much slower if it resulted from a primary infection than when it was caused by several local secondary infec-

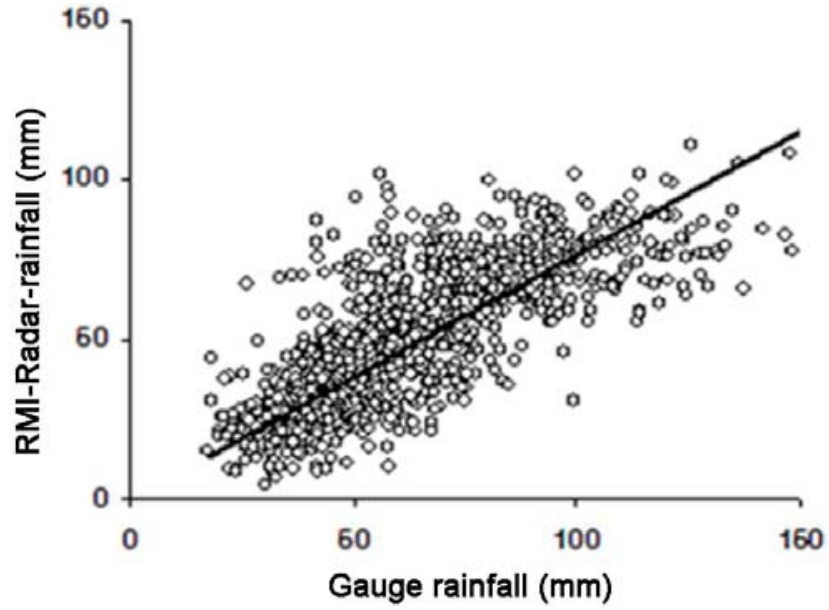

Fig. 2. Relationship between rain gauge and weather radar of the Royal Meteorological Institute (RMI) of Belgium measured at 77 weather stations in the network of the Hydrological Service of the Walloon Region of Belgium from 1 March to 31 July during three cropping seasons in 2003, 2004, and $2005\left(R^{2}=0.75, P<0.001\right)$.

Table 2. Comparison between rainfall events (amount and occurrence) calculated from cumulative hourly data estimated by the weather radar of the Royal Meteorological Institute of Belgium (IRM) and measurements from 77 rain gauges of the Hydrological Service of the Walloon Region of Belgium (SETHY), during the cropping seasons in 2003, 2004, and 2005

\begin{tabular}{|c|c|c|c|c|c|}
\hline Year, month & $\mathbf{R} / \mathbf{G}^{\mathbf{a}}$ & POD $^{\mathbf{b}}$ & FAR $^{\mathbf{c}}$ & CSII $^{\mathbf{d}}$ & $N^{\mathrm{e}}$ \\
\hline \multicolumn{6}{|l|}{2003} \\
\hline March & 0.86 & 0.67 & 0.35 & 0.49 & 54,775 \\
\hline April & 0.91 & 0.74 & 0.37 & 0.52 & 54,402 \\
\hline May & 0.92 & 0.80 & 0.28 & 0.61 & 53,260 \\
\hline June & 1.12 & 0.69 & 0.39 & 0.47 & 54,272 \\
\hline July & 0.75 & 0.78 & 0.28 & 0.60 & 55,588 \\
\hline All & 0.91 & 0.74 & 0.34 & 0.54 & 274,300 \\
\hline \multicolumn{6}{|l|}{2004} \\
\hline March & 0.66 & 0.57 & 0.40 & 0.41 & 55,499 \\
\hline April & 0.87 & 0.74 & 0.27 & 0.58 & 53,592 \\
\hline May & 0.50 & 0.70 & 0.26 & 0.56 & 57,211 \\
\hline June & 1.07 & 0.79 & 0.33 & 0.56 & 55,363 \\
\hline July & 0.81 & 0.79 & 0.33 & 0.56 & 52,668 \\
\hline All & 0.78 & 0.72 & 0.32 & 0.53 & 276,337 \\
\hline \multicolumn{6}{|l|}{2005} \\
\hline March & 0.57 & 0.44 & 0.44 & 0.32 & 56,955 \\
\hline April & 0.88 & 0.68 & 0.28 & 0.53 & 51,667 \\
\hline May & 0.84 & 0.73 & 0.24 & 0.60 & 49,049 \\
\hline June & 0.84 & 0.74 & 0.32 & 0.55 & 54,945 \\
\hline July & 0.64 & 0.73 & 0.21 & 0.61 & 54,898 \\
\hline All & 0.76 & 0.66 & 0.30 & 0.52 & 269,519 \\
\hline
\end{tabular}

${ }^{a}$ Radar/gauge $(\mathrm{R} / \mathrm{G})$ ratio calculated as the mean value for monthly accumulated radar estimates against rain-gauge data. A value greater than 1 indicates an overestimation of rainfall by radar.

${ }^{\mathrm{b}}$ Probability of detection (POD) is the probability of forecasting rainfall events correctly from radar data. It ranges from 0 to 1 , with $1=$ a perfect forecast.

${ }^{\mathrm{c}}$ False alarm ratio (FAR) is the number of times a rainfall event was detected by weather radar but not measured by rain-gauge, divided by the total number of forecasts of that event. Perfect value $=0$.

${ }^{\mathrm{d}}$ Critical success index (CSI) takes into account both false alarms and missed events. It ranges from 0 to 1 , with $1=$ perfect value.

${ }^{\mathrm{e}}$ Number of hourly rainfall events analyzed for comparing the radar estimates with precipitation measured by rain-gauges from 1 March to 31 July in three cropping seasons in 2003, 2004, and 2005. 
tions (36). To estimate the date of infection, the number of days corresponding to the latency period was calculated by the model and deducted from the date of significant increase in disease severity. The match with possible infection periods calculated by the model was then checked.

It is important to note that, between two field observations, two or three infection periods may be expressed (10). Therefore, in order to verify the model's ability to simulate infection at the right time, additional field observations were made at the four field sites to check the first appearance of symptoms with the model's simulation of the first appearance of the disease on leaves L3 to L1 (10).

For the comparison between radar and rain-gauge data in the simulated infection periods with PROCULTURE, the three classes in the contingency table (40)—a, b, and c-were called $a_{s}, b_{s}$, and $\mathrm{c}_{\mathrm{s}}$; therefore, the simulated POD, FAR, and CSI $\left(\mathrm{POD}_{\mathrm{s}}, \mathrm{FAR}_{\mathrm{s}}\right.$, and $\mathrm{CSI}_{\mathrm{s}}$, respectively) were expressed as:

$\mathrm{POD}_{\mathrm{s}}=\mathrm{a}_{\mathrm{s}} /\left(a_{\mathrm{s}}+c_{\mathrm{s}}\right) ; \mathrm{FAR}_{\mathrm{s}}=b_{\mathrm{s}} /\left(a_{\mathrm{s}}+b_{\mathrm{s}}\right) ; \mathrm{CSI}_{\mathrm{s}}=a_{\mathrm{s}} /\left(a_{\mathrm{s}}+b_{\mathrm{s}}+c_{\mathrm{s}}\right)$

where $a_{\mathrm{s}}=$ infection occurrences simulated when using both radar and rain-gauges, $b_{\mathrm{s}}=$ infection occurrences simulated when using radar but not simulated when using rain gauges, and $c_{\mathrm{s}}=$ infection occurrences not simulated when using radar but simulated when using rain gauges.

The same contingency table (40) was used to compare radarand gauge-derived simulated infections with infections assessed from observed leaf spot. However, here the simulation-observed POD, FAR, and CSI ( $\mathrm{POD}_{\mathrm{so}}, \mathrm{FAR}_{\mathrm{so}}$, and $\mathrm{CSI}_{\mathrm{so}}$, respectively) were expressed as:

$\mathrm{POD}_{\mathrm{so}}=a_{\mathrm{so}} /\left(a_{\mathrm{so}}+c_{\mathrm{so}}\right) ; \mathrm{FAR}_{\mathrm{so}}=b_{\mathrm{so}} /\left(a_{\mathrm{so}}+b_{\mathrm{so}}\right) ;$

$\mathrm{CSI}_{\mathrm{so}}=a_{\mathrm{so}} /\left(a_{\mathrm{so}}+b_{\mathrm{so}}+c_{\mathrm{so}}\right)$ where $a_{\text {so }}=$ infections both observed and simulated, $b_{\text {so }}=$ infections simulated but not observed, and $c_{\mathrm{so}}=$ infections observed but not simulated (40).

Infection occurrence was also assessed using a $t$ test with a threshold of $\alpha=0.05$ performed on consecutive field observations to verify the significance of the increment (10). Finally, the effects of location and year were tested by analysis of variance using PROC MIXED or linear regression (PROC REG) between the radar and weather stations using the software package SAS (version 9.1; SAS Institute Inc., Cary, NC).

\section{Results}

Comparison of weather-radar rainfall estimates with raingauge measurements. The linear regression between the rainfall estimates by RMI radar and the amounts measured by rain gauges over the three cropping seasons values was significant $(P<0.001)$, and the coefficient of determination $\left(R^{2}\right)$ explained $75 \%$ of the variability (Fig. 2). The radar monthly rainfall amount (Table 2) showed an R/G ratio, calculated as the mean value over all stations, ranging between 0.50 and 1.12 for all events and stations tested (a value greater than 1 indicated an overestimation of rainfall by radar). A more detailed analysis revealed a monthly $(P<0.001)$ and annual variability $(P<0.05)$ in the $\mathrm{R} / \mathrm{G}$ ratio over the 3 years. This variability was also evident for the weather stations. Averaged over the study, the mean $\mathrm{R} / \mathrm{G}$ was 0.82 , corresponding to a mean radar underestimation of precipitation of $18 \%$ (Table 2). A significant reduction in the accuracy of the radar estimates $(P<0.05)$ was found for stations located more than $120 \mathrm{~km}$ from the radar (data not shown).

Rainfall occurrence was assessed using both hourly weatherradar and rain-gauge data from weather stations. The POD values

Table 3. Hourly precipitation contingency table (\%) for both the rain-gauge of the Hydrological Service of the Walloon Region of Belgium (SETHY) and the rainfall occurrence estimated by the weather radar of Royal Meteorological Institute of Belgium (RMI) ${ }^{\mathrm{a}}$

\begin{tabular}{|c|c|c|c|c|c|c|c|c|c|}
\hline \multirow[b]{2}{*}{ Year, $\mathbf{R} \backslash \mathbf{G}^{\mathbf{c}}$} & \multicolumn{9}{|c|}{ Contingency $(\%)$ at each precipitation level ${ }^{b}$} \\
\hline & $\mathbf{0}$ & $(0-0.1)$ & $(0.1-0.2)$ & $(0.2-0.3)$ & $(0.3-0.4)$ & $(0.4-0.5)$ & $(0.5-1)$ & $(1-2)$ & $>0.2$ \\
\hline \multicolumn{10}{|l|}{$2003^{\mathrm{d}}$} \\
\hline 0 & 86.42 & $\underline{1.74}$ & $\underline{0.27}$ & $\underline{0.15}$ & $\underline{0.07}$ & $\underline{0.05}$ & $\underline{0.09}$ & $\underline{0.07}$ & $\underline{0.09}$ \\
\hline$(0-0.1)$ & 2.36 & $\overline{0.64}$ & $\overline{0.24}$ & $\overline{0.14}$ & $\overline{0.07}$ & $\overline{0.05}$ & $\overline{0.11}$ & $\overline{0.04}$ & $\overline{0.01}$ \\
\hline$(0.1-0.2)$ & 0.57 & 0.32 & 0.18 & 0.11 & 0.08 & 0.05 & 0.12 & 0.05 & 0.01 \\
\hline$(0.2-0.3)$ & 0.26 & 0.18 & 0.14 & 0.11 & 0.07 & 0.05 & 0.12 & 0.06 & 0.01 \\
\hline$(0.3-0.4)$ & 0.10 & 0.09 & 0.10 & 0.09 & 0.07 & 0.05 & 0.12 & 0.07 & 0.01 \\
\hline$(0.4-0.5)$ & 0.08 & 0.05 & 0.06 & 0.06 & 0.05 & 0.04 & 0.11 & 0.07 & 0.02 \\
\hline$(0.5-1)$ & 0.13 & 0.07 & 0.10 & 0.11 & 0.13 & 0.11 & 0.46 & 0.36 & 0.10 \\
\hline$(1-2)$ & 0.09 & 0.02 & 0.01 & 0.02 & 0.03 & 0.03 & 0.24 & 0.50 & 0.34 \\
\hline$>0.2$ & 0.04 & 0.01 & 0.01 & 0.00 & 0.01 & 0.00 & 0.04 & 0.16 & 0.55 \\
\hline \multicolumn{10}{|l|}{$2004^{e}$} \\
\hline 0 & 83.76 & 2.38 & $\underline{0.48}$ & $\underline{0.21}$ & $\underline{0.13}$ & $\underline{0.08}$ & $\underline{0.17}$ & 0.09 & $\underline{0.08}$ \\
\hline$(0-0.1)$ & 2.67 & $\overline{0.82}$ & $\overline{0.36}$ & $\overline{0.21}$ & $\overline{0.12}$ & $\overline{0.07}$ & $\overline{0.18}$ & $\overline{0.05}$ & $\overline{0.01}$ \\
\hline$(0.1-0.2)$ & 0.64 & 0.41 & 0.23 & 0.16 & 0.11 & 0.07 & 0.19 & 0.07 & 0.02 \\
\hline$(0.2-0.3)$ & 0.27 & 0.21 & 0.18 & 0.12 & 0.09 & 0.06 & 0.18 & 0.07 & 0.03 \\
\hline$(0.3-0.4)$ & 0.14 & 0.10 & 0.10 & 0.08 & 0.07 & 0.06 & 0.15 & 0.09 & 0.02 \\
\hline$(0.4-0.5)$ & 0.07 & 0.06 & 0.07 & 0.06 & 0.06 & 0.05 & 0.15 & 0.09 & 0.03 \\
\hline$(0.5-1)$ & 0.14 & 0.09 & 0.10 & 0.12 & 0.13 & 0.13 & 0.49 & 0.40 & 0.19 \\
\hline$(1-2)$ & 0.06 & 0.01 & 0.02 & 0.02 & 0.03 & 0.04 & 0.25 & 0.41 & 0.30 \\
\hline$>0.2$ & 0.02 & 0.00 & 0.00 & 0.00 & 0.00 & 0.00 & 0.05 & 0.13 & 0.46 \\
\hline \multicolumn{10}{|l|}{$2005^{\mathrm{f}}$} \\
\hline 0 & 83.28 & $\underline{2.88}$ & $\underline{0.68}$ & $\underline{0.36}$ & $\underline{0.21}$ & $\underline{0.13}$ & $\underline{0.25}$ & $\underline{0.10}$ & $\underline{0.05}$ \\
\hline$(0-0.1)$ & 2.38 & 0.86 & 0.43 & 0.22 & 0.16 & 0.11 & 0.20 & 0.06 & 0.01 \\
\hline$(0.1-0.2)$ & 0.55 & 0.38 & 0.24 & 0.17 & 0.12 & 0.08 & 0.18 & 0.07 & 0.01 \\
\hline$(0.2-0.3)$ & 0.22 & 0.18 & 0.16 & 0.13 & 0.11 & 0.07 & 0.20 & 0.08 & 0.01 \\
\hline$(0.3-0.4)$ & 0.09 & 0.09 & 0.10 & 0.08 & 0.08 & 0.06 & 0.18 & 0.08 & 0.01 \\
\hline$(0.4-0.5)$ & 0.06 & 0.04 & 0.05 & 0.06 & 0.06 & 0.06 & 0.18 & 0.09 & 0.02 \\
\hline$(0.5-1)$ & 0.10 & 0.05 & 0.06 & 0.09 & 0.10 & 0.11 & 0.51 & 0.44 & 0.11 \\
\hline$(1-2)$ & 0.05 & 0.01 & 0.01 & 0.02 & 0.02 & 0.02 & 0.21 & 0.42 & 0.30 \\
\hline$>0.2$ & 0.03 & 0.00 & 0.00 & 0.01 & 0.00 & 0.00 & 0.03 & 0.11 & 0.47 \\
\hline
\end{tabular}

${ }^{a}$ Contingency table covers 1 March to 31 July in 2003, 2004, and 2005 for all stations. Numbers in parentheses indicate that precipitation was $>0$ and $\leq 0.1 \mathrm{~mm}$.

b Bold, underlined, and italic values indicate the false alarms, misses, and hits, respectively, estimated by RMI weather radar per classes of precipitation.

${ }^{\mathrm{c}} \mathrm{R}=$ the RMI-Radar rainfall amount estimates (in $\mathrm{mm}$ ); and $\mathrm{G}=$ the SETHY rain-gauge precipitation amount measurements (in $\mathrm{mm}$ ).

${ }^{\mathrm{d}}$ Data from 77 rain-gauges and 274,300 events considered.

e Data from 77 rain-gauges and 276,337 events considered.

${ }^{f}$ Data from 77 rain-gauges and 269,519 events considered. 
of rainfall events varied from 0.44 to 0.80 throughout the study (average $=0.71 \pm 0.09$ ). The results in Table 2 demonstrate monthly variations, with lower values in March. This acceptable POD, however, was accompanied by a high FAR (0.21 to 0.44$)$, which may be explained by the low rainfall that was close to the limit of detectability by the rain gauges. This was clearly expressed in the hourly precipitation contingency table showing the relationship between gauge- and radar-derived hourly rainfall estimates (Table 3). The largest discrepancies between the two sets of measurements were observed for very weak intensity rainfall ( 0 to 0.1 $\mathrm{mm}$; Table 3 ). When the hourly rainfall threshold indicating a rainfall event was increased (i.e., a rainfall event was considered when $>0.1 \mathrm{~mm}$ ), the FAR scores were reduced from $0.32 \pm 0.06$ to $0.13 \pm$ 0.04 . This improvement was also observed for the POD (from 0.71 \pm 0.09 to $0.87 \pm 0.08$ on average) and CSI (from $0.53 \pm 0.08$ to $0.76 \pm 0.08$, on average) (Fig. 3).

Comparison of radar- and gauge-derived data in simulated infection periods. Using gauge-derived infection periods as the reference, the comparison with radar-derived data resulted in an average $\mathrm{POD}_{\mathrm{s}}$ of infection events of 0.83 for all periods and sites tested. It also, however, gave a non-negligible $\mathrm{FAR}_{\mathrm{s}}$ of 0.24 (Table 4). In 2003, Humain was the site with the highest scores $\left(\mathrm{CSI}_{\mathrm{s}}=\right.$ 0.85), while Libramont had the lowest scores, with $\mathrm{CSI}_{\mathrm{s}}=0.48$. This inferred that, in Humain, in $85 \%$ of case, infection events were simulated at the same date regardless of the rainfall instrument used; whereas, in Libramont, only $48 \%$ of infection periods were correctly simulated by the radar, assuming that the rainfall reference was given by rain gauges. In 2004, Echternach had the highest scores $\left(\mathrm{CSI}_{\mathrm{s}}=\right.$ $0.76)$ and Libramont again had the lowest $\left(\mathrm{CSI}_{\mathrm{s}}=0.47\right)$. In 2005 , Dourbes had the highest scores $\left(\mathrm{CSI}_{\mathrm{s}}=0.88\right)$ and Libramont was also the worst $\left(\mathrm{CSI}_{\mathrm{s}}=0.53\right)$. Finally, the seven stations showed a significant difference among years $(P<0.05, t$ test) (Humain, Sommethonne, Soignies, Thuin, Ernage, Chimay, and Gouvy).
Evaluation of radar- and gauge-derived infection simulations against observed leaf spot symptoms. Field monitoring of the visually estimated leaf area covered by disease lesions on the five upper leaves at four sites from 2003 to 2005 revealed significant differences among years, and a significant interaction between years and sites $(P<0.001$; Table 5$)$. Analysis of the changes in disease severity identified 148 new infection events on the upper three leaves (Tables 5 and 6). Overall, the duration of periods with a high probability of infection calculated by PROCULTURE on the basis of radar rainfall data for these trials was similar to that based on gauge measurements (Table 6; Fig. 4), confirming the results presented in Table 4. At Humain, out of 42 infection events over the three cropping seasons, $90 \%$ were correctly predicted by PROCULTURE using the weather-radar data, while only $84 \%$ were correctly anticipated using rain gauges. Only $4 \%$ of infection events predicted by PROCULTURE using radar estimates as input data were not confirmed by visual observations of symptoms. For the three other sites (Useldange, Burmerange, and Reuler), for 48, 37 and 21 infection events, respectively, the radar was always more accurate than the rain gauges in simulating infection risks.

The FAR ${ }_{\text {so }}$ index was 0 for all stations, except for the radar data at Humain in 2005 and for both the gauge and radar data at Useldange in 2005. Although the $\mathrm{POD}_{\text {so }}$ was, on average, 0.84 for all stations when using the radar estimates as input data for the PROCULTURE model, the $\mathrm{POD}_{\text {so }}$ fell to 0.79 when using the raingauge data. There was no significant difference $(P>0.05)$ in the number of infection events of simulations using rainfall data derived from either radar assessments or rain-gauge measurements.

\section{Discussion}

Due to the high spatial variability of rainfall, particularly for convective events during the growing season in Belgium and Luxembourg, data from the existing rain-gauge network may miss rain
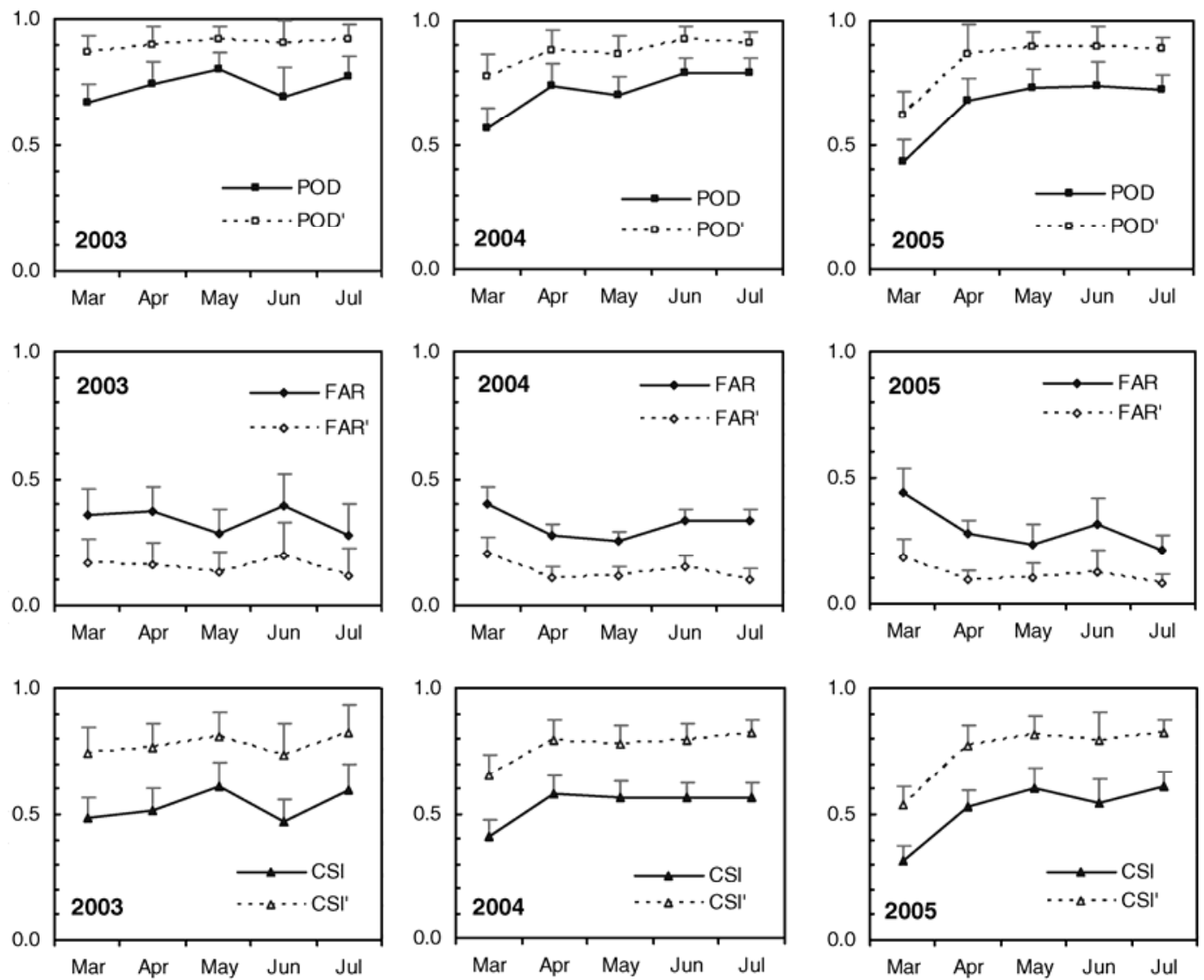

Fig. 3. Adjusted verification scores. POD', FAR', and CSI' are the adjusted probability of detection (POD), false alarm ratio (FAR), and critical success index (CSI) values, respectively, obtained when raising the minimum rainfall threshold. Values of POD', FAR', and CSI' were calculated by considering only those hours when the weather-radar rainfall estimates and rain-gauge precipitation measurements both exceeded $0.1 \mathrm{~mm}$. 
events in some localities and be inadequate for delivering rapid advice to farmers who are not located near a gauge. The assessment of the PROCULTURE model at several sites in Belgium and Luxembourg over several years has shown that it can explain disease progression in the canopy $(3,10,22,26,29)$. The PROCULTURE model is being used in early warning systems in Belgium and Luxembourg to define, in real time, the risk of SLB on the upper leaves of winter wheat during stem elongation (10). Setting up an operational network, however, for recommending the optimal time for fungicide application in Belgium and Luxembourg requires a representative network of weather stations throughout the territory. Important points to consider in the territorial deployment of epidemiological models in disease management include (i) the many possible sources of error with both radar- and gauge-derived precipitation measurements; (ii) weather radar may provide predictions of infection event occurrences comparable with those obtained from weather stations; and (iii), as this study shows, RMI radar may be used in a complementary manner to rain-gauge networks but not as a complete substitute. Analyses revealed spatial and temporal variability in the R/G ratio and showed a general underestimation of radar-derived rainfall amounts compared with gauge-derived data. In addition, the POD of rainfall occurrence varied from 0.44 to 0.80 and the FAR values were relatively high (from 0.21 to 0.44 ), which may be explained by extremely low rainfall events. However, if a minimum threshold of $0.1 \mathrm{~mm}$ is fixed for a rainfall event to occur effectively, the average POD' $^{\prime}$ of

Table 4. Comparison between Mycosphaerella graminicola infection periods (in hours on the upper three leaves) simulated by PROCULTURE using radar estimates and measurements from 14 rain-gauge stations for the cropping seasons in 2003, 2004, and 2005 ${ }^{\mathrm{a}}$

\begin{tabular}{|c|c|c|c|c|c|}
\hline Years, stations ${ }^{\text {b }}$ & Gauge $^{c}$ & Radar $^{d}$ & POD $_{s}{ }^{\mathrm{e}}$ & FAR $_{\mathrm{s}}{ }^{\mathrm{f}}$ & $\mathrm{CSI}_{\mathrm{s}} \mathrm{g}^{\mathrm{g}}$ \\
\hline \multicolumn{6}{|l|}{2003} \\
\hline Burmerange & 45 & 38 & 0.83 & 0.23 & 0.67 \\
\hline Chimay & 92 & 92 & 0.86 & 0.14 & 0.75 \\
\hline Dourbes & 84 & 93 & 0.96 & 0.19 & 0.79 \\
\hline Echternach & 49 & 57 & 1.00 & 0.21 & 0.79 \\
\hline Ernage & 90 & 111 & 0.90 & 0.18 & 0.76 \\
\hline Gouvy & 76 & 63 & 0.68 & 0.25 & 0.56 \\
\hline Havelange & 120 & 85 & 0.63 & 0.14 & 0.58 \\
\hline Humain & 106 & 118 & 0.97 & 0.13 & 0.85 \\
\hline Libramont & 87 & 67 & 0.63 & 0.33 & 0.48 \\
\hline Reuler & - & - & - & - & - \\
\hline Soignies & 85 & 89 & 0.83 & 0.17 & 0.71 \\
\hline Sommethonne & 78 & 86 & 0.86 & 0.25 & 0.67 \\
\hline Thuin & 99 & 108 & 0.88 & 0.17 & 0.75 \\
\hline Useldange & 77 & 59 & 0.76 & 0.16 & 0.67 \\
\hline Total & 1,088 & 1,066 & 0.83 & 0.20 & 0.69 \\
\hline \multicolumn{6}{|l|}{2004} \\
\hline Burmerange & 61 & 82 & 0.90 & 0.33 & 0.62 \\
\hline Chimay & 80 & 87 & 0.87 & 0.26 & 0.67 \\
\hline Dourbes & 67 & 60 & 0.84 & 0.20 & 0.70 \\
\hline Echternach & 47 & 53 & 0.89 & 0.16 & 0.76 \\
\hline Ernage & 63 & 85 & 0.96 & 0.30 & 0.68 \\
\hline Gouvy & 62 & 68 & 0.81 & 0.32 & 0.59 \\
\hline Havelange & 82 & 79 & 0.76 & 0.31 & 0.56 \\
\hline Humain & 81 & 77 & 0.91 & 0.23 & 0.71 \\
\hline Libramont & 99 & 65 & 0.67 & 0.38 & 0.47 \\
\hline Reuler & 81 & 65 & 0.83 & 0.32 & 0.60 \\
\hline Soignies & 75 & 64 & 0.64 & 0.25 & 0.53 \\
\hline Sommethonne & 70 & 73 & 0.75 & 0.33 & 0.55 \\
\hline Thuin & 71 & 67 & 0.84 & 0.30 & 0.62 \\
\hline Useldange & 75 & 72 & 0.83 & 0.21 & 0.68 \\
\hline Total & 1,014 & 997 & 0.82 & 0.28 & 0.62 \\
\hline \multicolumn{6}{|l|}{2005} \\
\hline Burmerange & 52 & 58 & 0.79 & 0.24 & 0.63 \\
\hline Chimay & 80 & 67 & 0.74 & 0.31 & 0.56 \\
\hline Dourbes & 64 & 70 & 0.91 & 0.05 & 0.88 \\
\hline Echternach & 42 & 51 & 0.94 & 0.20 & 0.76 \\
\hline Ernage & 48 & 78 & 0.94 & 0.45 & 0.53 \\
\hline Gouvy & 79 & 62 & 0.88 & 0.19 & 0.73 \\
\hline Havelange & 43 & 62 & 0.74 & 0.33 & 0.54 \\
\hline Humain & 75 & 73 & 0.93 & 0.11 & 0.83 \\
\hline Libramont & 77 & 67 & 0.69 & 0.31 & 0.53 \\
\hline Reuler & 81 & 62 & 0.86 & 0.14 & 0.75 \\
\hline Soignies & 77 & 73 & 0.72 & 0.25 & 0.58 \\
\hline Sommethonne & 102 & 89 & 0.94 & 0.21 & 0.75 \\
\hline Thuin & 73 & 80 & 0.79 & 0.21 & 0.65 \\
\hline Useldange & 68 & 64 & 0.83 & 0.20 & 0.69 \\
\hline Total & 961 & 956 & 0.84 & 0.23 & 0.67 \\
\hline
\end{tabular}

a Verification statistic indices—probability of detection $\left(\mathrm{POD}_{\mathrm{i}}\right)$, false alarm ratio $\left(\mathrm{FAR}_{\mathrm{i}}\right)$, and critical success index $\left(\mathrm{CSI}_{\mathrm{i}}\right)$-show agreement between rain gauges and radar-derived duration periods with a high probability of $M$. graminicola infection. Average for each cropping season indicated in bold; - indicates missing data.

${ }^{\mathrm{b}}$ Burmerange $=$ CRP-Gabriel Lippmann station in Belgium; Chimay, Gouvy, Havelange, Libramont, Soignies, Sommethonne, and Thuin $=$ Promotion of Agrometeorology in Southeastern Belgium stations in Belgium; Dourbes, Ernage, and Humain = Royal Meteorological Institute (RMI) stations in Belgium; and Echternach, Reuler, and Useldange = Administration des Services Techniques de l'Agriculture stations in Luxembourg.

${ }^{c}$ Total number of hours with a high probability of infection simulated when using rain-gauge precipitation data.

d Total number of hours with a high probability of infection simulated when using RMI radar rainfall data.

e POD of $M$. graminicola infection simulated by PROCULTURE.

${ }^{\mathrm{f}}$ FAR of $M$. graminicola infection simulated by PROCULTURE.

g CSI of M. graminicola infection simulated by PROCULTURE. 
Table 5. Visually estimated leaf area (\%) covered by sporulating Mycosphaerella graminicola lesions on L5 to L1 for the winter wheat cultivars Achat, Bussard, Centenaire, Cubus, Dekan, Drifter, and Flair in 2003, 2004, and 2005 at the trial sites of Burmerange, Humain, Reuler, and Useldange

\begin{tabular}{|c|c|c|c|c|c|c|c|c|c|c|}
\hline \multirow{2}{*}{$\begin{array}{l}\text { Year } \\
\text { Site, cv., date } \\
\text { Leaf }{ }^{a}\end{array}$} & \multicolumn{2}{|c|}{ April } & \multicolumn{2}{|c|}{ May } & \multicolumn{5}{|c|}{ June } & \multirow{2}{*}{$\begin{array}{c}\text { July } \\
7\end{array}$} \\
\hline & 7 & 22 & 5 & 19 & 2 & 10 & 16 & 23 & 30 & \\
\hline \multicolumn{11}{|l|}{$\overline{2003}$} \\
\hline \multicolumn{11}{|c|}{ Burmerange, Dekan, 12 May } \\
\hline L5 & - & $0.1 * \mathrm{~b}$ & 0.3 & $8.1 *$ & $36^{*}$ & $69 *$ & - & _- & _- & _- \\
\hline L4 & - & - & - & - & $2.6^{*}$ & $19^{*}$ & $59 *$ & - & - & - \\
\hline L3 & - & - & - & - & $0.7^{*}$ & $5.3 *$ & $25^{*}$ & $41^{*}$ & $53^{*}$ & - \\
\hline L2 & - & - & - & - & $0.1 *$ & 0.8 & $5.4 *$ & $14 *$ & $28^{*}$ & - \\
\hline L1 & - & - & - & - & $0.0^{*}$ & 0.1 & 0.4 & $1.7^{*}$ & $5.8^{*}$ & - \\
\hline \multicolumn{11}{|c|}{ Reuler, Bussard, 2 June } \\
\hline L5 & - & - & - & - & $0.9 *$ & $9.4^{*}$ & - & - & - & - \\
\hline L4 & - & - & - & - & $0.4 *$ & 0.9 & $68^{*}$ & - & - & - \\
\hline L3 & - & - & - & - & - & $0.2 *$ & $16^{*}$ & $26 *$ & 31 & 39 \\
\hline L2 & _- & _- & _- & _- & _- & - & $1.5^{*}$ & $10^{*}$ & 7 & $25^{*}$ \\
\hline L1 & - & - & - & - & - & - & - & $0.3 *$ & 0.2 & $8.9 *$ \\
\hline \multicolumn{11}{|c|}{ Humain, Centenaire, 2 June } \\
\hline L5 & - & - & - & - & $10^{*}$ & - & - & _- & - & $\ldots$ \\
\hline L4 & - & - & - & - & $2.3^{*}$ & - & - & - & - & $\ldots$ \\
\hline L3 & - & - & - & - & $0.3 *$ & 0.1 & $\ldots$ & $25^{*}$ & $\ldots$ & $88^{*}$ \\
\hline L2 & - & - & - & - & - & $0.1^{*}$ & $\ldots$ & $11^{*}$ & $\ldots$ & $54^{*}$ \\
\hline L1 & - & - & - & - & - & $0.1^{*}$ & $\ldots$ & $0.8^{*}$ & $\ldots$ & $11^{*}$ \\
\hline \multicolumn{11}{|c|}{ Useldange, Achat, 19 May } \\
\hline L5 & - & $0.0^{*}$ & 0.4 & $13^{*}$ & $68^{*}$ & $84 *$ & - & - & - & - \\
\hline L4 & - & - & - & $0.3 *$ & $35^{*}$ & 43 & - & - & - & - \\
\hline L3 & - & - & - & $0.4 *$ & $11^{*}$ & $21^{*}$ & $57 *$ & $83^{*}$ & - & - \\
\hline $\mathrm{L} 2$ & - & - & - & - & $1.1 *$ & 3.3 & $19 *$ & $53^{*}$ & $62 *$ & $76^{*}$ \\
\hline \multirow[t]{3}{*}{ L1 } & - & - & - & - & $0.6^{*}$ & $3.6^{*}$ & $9.4^{*}$ & $21^{*}$ & $45^{*}$ & $70^{*}$ \\
\hline & & & & & & & June & & & July \\
\hline & 9 & 26 & 10 & 17 & 1 & 7 & $\ldots$ & 22 & 28 & 12 \\
\hline 2004 & & & & & & & & & & \\
\hline Burmerange, $\mathrm{C}$ & & & & & & & & & & \\
\hline L5 & $0.0^{*}$ & 0.2 & $1.5^{*}$ & $9.0^{*}$ & $45^{*}$ & $100 *$ & $\ldots$ & - & - & - \\
\hline L4 & - & - & - & $0.7 *$ & $11 *$ & $30 *$ & $\ldots$ & - & - & _- \\
\hline L3 & - & - & - & $0.2^{*}$ & $3.4 *$ & $7.7^{*}$ & $\ldots$ & $29 *$ & $69^{*}$ & - \\
\hline L2 & - & - & - & - & $1.1^{*}$ & 2.8 & $\ldots$ & $15^{*}$ & $41 *$ & $62 *$ \\
\hline L1 & - & - & - & - & $0.1 *$ & 0.4 & $\ldots$ & $1.2 *$ & $7.9 *$ & $33 *$ \\
\hline Reuler, Bussard & & & & & & & & & & \\
\hline L5 & - & - & $0.0^{*}$ & $1.1 *$ & $28 *$ & $61 *$ & $\ldots$ & $100 *$ & - & - \\
\hline L4 & - & - & - & $0.1^{*}$ & $5.4^{*}$ & $17 *$ & $\ldots$ & $27 *$ & $100 *$ & - \\
\hline L3 & _- & - & - & - & $0.3^{*}$ & $1.5^{*}$ & $\ldots$ & 3.2 & 4.9 & $63 *$ \\
\hline L2 & - & - & - & - & - & - & $\ldots$ & $0.0 *$ & 0.6 & $28^{*}$ \\
\hline L1 & - & - & - & - & - & - & $\ldots$ & - & $0.1^{*}$ & $3.0^{*}$ \\
\hline Humain, Drifte & & & & & & & & & & \\
\hline L5 & - & $0.9^{*}$ & $17^{*}$ & - & - & - & $\ldots$ & - & - & - \\
\hline L4 & _- & - & $2.1 *$ & 2.4 & $9.0^{*}$ & - & $\ldots$ & - & - & - \\
\hline L3 & - & - & $0.1^{*}$ & 0.1 & $9.4 *$ & 9.0 & $\ldots$ & $28^{*}$ & 35 & $53^{*}$ \\
\hline L2 & _- & - & - & - & $1.4^{*}$ & 1.0 & $\ldots$ & $6.0^{*}$ & 10 & $36^{*}$ \\
\hline L1 & - & - & - & - & - & - & $\ldots$ & $0.4 *$ & $2.7 *$ & $5.2 *$ \\
\hline Useldange, Ach & & & & & & & & & & \\
\hline L5 & - & - & $1.4^{*}$ & $20 *$ & $100 *$ & - & $\ldots$ & - & - & - \\
\hline L4 & - & - & - & $0.9 *$ & $25^{*}$ & $51^{*}$ & $\ldots$ & - & - & - \\
\hline L3 & _- & - & - & - & $5.6^{*}$ & $10^{*}$ & $\ldots$ & $55^{*}$ & 52 & - \\
\hline L2 & - & - & - & - & $1.3^{*}$ & 2.2 & $\ldots$ & $8.3^{*}$ & 9.5 & 39 \\
\hline L1 & - & - & - & - & - & $0.0^{*}$ & $\ldots$ & 0.2 & $2.0^{*}$ & $7.9^{*}$ \\
\hline & & & & May & & & & & & July \\
\hline & 4 & 25 & 9 & 17 & 30 & 6 & 13 & 20 & 27 & 4 \\
\hline 2005 & & & & & & & & & & \\
\hline Burmerange, $\mathrm{C}$ & & & & & & & & & & \\
\hline L5 & - & $2.2 *$ & $9.7 *$ & $55^{*}$ & $99 *$ & - & - & - & - & - \\
\hline L4 & - & - & $0.2 *$ & $15^{*}$ & $74 *$ & $90^{*}$ & - & - & - & - \\
\hline L3 & - & - & - & $6.0 *$ & $28^{*}$ & $38^{*}$ & 36 & $72 *$ & 66 & - \\
\hline L2 & - & - & - & $1.0^{*}$ & 0.5 & 1.1 & 3.8 & $25^{*}$ & $46^{*}$ & $60 *$ \\
\hline $\mathrm{L} 1$ & - & - & - & - & - & $0.0^{*}$ & 0.7 & $3.0^{*}$ & $14^{*}$ & $33^{*}$ \\
\hline Reuler, Flair, 30 & & & & & & & & & & \\
\hline L5 & - & $0.1^{*}$ & $1.6^{*}$ & $21^{*}$ & $93 *$ & - & - & - & - & - \\
\hline & & & & & & & & & (continued & ext page) \\
\hline
\end{tabular}

${ }^{a}$ Year, site, cultivar, date of appearance of the flag leaf ligule/collar (GS39), and leaf stage. The Burmerange, Reuler, and Useldange sites are in Luxembourg and the Humain site is in Belgium.

${ }^{\mathrm{b}}$ Asterisks $(*)$ indicate a significant difference $(P<0.05)$ between two successive observations. Decimals are given only when percentage of disease severity is lower than $10 \%$. 
Table 5. (continued from preceding page)

\begin{tabular}{|c|c|c|c|c|c|c|c|c|c|c|}
\hline \multirow{2}{*}{$\begin{array}{l}\text { Year } \\
\text { Site, cv., date } \\
\text { Leaf }^{a}\end{array}$} & \multicolumn{2}{|c|}{ April } & \multicolumn{2}{|c|}{ May } & \multicolumn{5}{|c|}{ June } & \multirow{2}{*}{$\frac{\text { July }}{7}$} \\
\hline & 7 & 22 & 5 & 19 & 2 & 10 & 16 & 23 & 30 & \\
\hline $\mathrm{L} 4$ & - & - & $1.2 *$ & $3.0 *$ & $37 *$ & 33 & $47 *$ & - & - & - \\
\hline L3 & - & - & - & $0.1 *$ & $5.6^{*}$ & 4.7 & 7.8 & $13^{*}$ & $27 *$ & - \\
\hline L2 & - & - & - & - & - & $0.1^{*}$ & 0.2 & 0.6 & $7.0^{*}$ & $41 *$ \\
\hline L1 & - & - & - & - & - & - & - & $0.0^{*}$ & $0.5^{*}$ & $3.0 *$ \\
\hline \multicolumn{11}{|c|}{ Humain, Drifter, 30 May } \\
\hline L5 & - & $0.6 *$ & $3.8 *$ & $30 *$ & - & - & - & - & - & - \\
\hline $\mathrm{L} 4$ & - & - & $0.4^{*}$ & $2.8 *$ & $37 *$ & $53 *$ & - & - & - & - \\
\hline L3 & - & - & - & $0.1 *$ & $4.5^{*}$ & 5.6 & $13^{*}$ & $35^{*}$ & $66^{*}$ & - \\
\hline $\mathrm{L} 2$ & - & - & - & - & $0.1^{*}$ & 0.1 & $2.4^{*}$ & $6.0^{*}$ & $22 *$ & 27 \\
\hline L1 & - & - & - & - & - & - & $0.1^{*}$ & 0.2 & 0.9 & $5.4^{*}$ \\
\hline \multicolumn{11}{|c|}{ Useldange, Achat, 23 May } \\
\hline L5 & - & $0.7 *$ & $20 *$ & $39 *$ & $98^{*}$ & - & - & - & - & - \\
\hline $\mathrm{L} 4$ & - & - & $2.2 *$ & $4.7 *$ & $81 *$ & 91 & - & - & - & - \\
\hline L3 & - & - & $0.1^{*}$ & 1.1 & $22 *$ & 26 & 25 & $44 *$ & $59 *$ & - \\
\hline L2 & - & - & - & - & $1.1^{*}$ & 0.7 & $4.5^{*}$ & $10 *$ & $32 *$ & $42 *$ \\
\hline L1 & - & - & - & - & - & - & $0.8^{*}$ & $2.7^{*}$ & $11 *$ & $24 *$ \\
\hline
\end{tabular}

rainfall events increased to $0.87 \pm 0.08$ (on average) and the FAR' fell to $0.14 \pm 0.04$ (on average) (Fig. 3). When the radar data were compared with the gauge data in the simulated infection period, the $\mathrm{POD}_{\mathrm{s}}$ was $83 \%$, with a non-negligible FAR of $24 \%$ (Table 4). This reduced to $2 \%\left(\mathrm{FAR}_{\mathrm{so}}\right)$ when the radar-derived infection simulations were evaluated against infection periods deduced from observed disease symptoms (Table 6).

The findings of this study largely concurred with those obtained by other researchers $(14,24,42)$. In addition to weather-radar error, missed infection events responsible for $\mathrm{POD}_{\text {so }}$ values $<1$ could also be explained by the model limits. For example, PROCULTURE's modeling considers only infections caused by $S$. tritici conidia, the anamorph stage of the fungus which causes the most damage $(10,29)$. However, ascospores released by rain from the teleomorph stage of M. graminicola which are then dispersed by wind could also lead to SLB development on the upper leaf layer in the absence of an increase in conidia-based inoculum on the lower leaves $(4,11,20,23)$. In addition, symptom expression could be a few days ( 2 to 3 days) earlier or delayed compared with the calculated dates, and may not be detected at the weekly monitoring. In this study, the outputs of PROCULTURE infection events using the weather radar seemed at least as relevant as those obtained when using rainfall data from the meteorological stations. However, no significant difference was detected between the two sets of input rainfall data for SLB risk assessment. This infers that, for a given location, radar rainfall estimates were as suitable for predicting infection events as gauge-based data. Therefore, with the advantage of weather radar being able to measure rainfall throughout an area

Table 6. Comparison of the performance in using rain-gauge or radar rainfall data in the PROCULTURE model for capturing Mycosphaerella graminicola infection events on winter wheat at four sites and during three cropping seasons ${ }^{\mathrm{a}}$

\begin{tabular}{|c|c|c|c|c|c|c|c|c|c|}
\hline \multirow[b]{2}{*}{ Site, observation period $f$} & \multirow[b]{2}{*}{ Events $\mathrm{g}$} & \multicolumn{2}{|c|}{${\text { Infection period }(h)^{b}}^{b}$} & \multicolumn{2}{|c|}{ POD $_{s o}{ }^{c}$} & \multicolumn{2}{|c|}{ FAR $_{\text {so }}{ }^{d}$} & \multicolumn{2}{|c|}{$\mathrm{CSI}_{\text {so }}{ }^{\mathrm{e}}$} \\
\hline & & Gauge & Radar & Gauge & Radar & Gauge & Radar & Gauge & Radar \\
\hline \multicolumn{10}{|l|}{ Humain } \\
\hline 21 May to 5 July 2003 & 18 & 60 & 62 & 0.93 & 0.83 & 0 & 0 & 0.93 & 0.83 \\
\hline 3 May to 28 June 2004 & 16 & 46 & 40 & 0.73 & 0.87 & 0 & 0 & 0.73 & 0.87 \\
\hline 20 May to 15 July 2005 & 8 & 24 & 27 & 0.86 & 1.00 & 0 & 0.12 & 0.85 & 0.87 \\
\hline Total & 42 & 130 & 129 & 0.84 & 0.90 & $\mathbf{0}$ & 0.04 & 0.84 & 0.86 \\
\hline \multicolumn{10}{|l|}{ Useldange } \\
\hline 13 May to 29 June 2003 & 15 & 56 & 44 & 0.87 & 0.80 & 0 & 0 & 0.87 & 0.80 \\
\hline 16 May to 9 July 2004 & 18 & 48 & 48 & 0.72 & 0.78 & 0 & 0 & 0.72 & 0.78 \\
\hline 14 May to 12 July 2005 & 15 & 33 & 32 & 0.71 & 0.86 & 0.09 & 0.07 & 0.67 & 0.81 \\
\hline Total & 48 & 137 & 124 & 0.77 & 0.81 & 0.03 & 0.02 & 0.75 & 0.80 \\
\hline \multicolumn{10}{|l|}{ Burmerange } \\
\hline 17 May to 3 July 2003 & 10 & 30 & 22 & 0.70 & 0.70 & 0 & 0 & 0.70 & 0.70 \\
\hline 5 May to 13 July 2004 & 15 & 43 & 55 & 0.73 & 0.93 & 0 & 0 & 0.73 & 0.93 \\
\hline 12 May to 4 July 2005 & 12 & 24 & 28 & 0.91 & 0.83 & 0 & 0 & 0.91 & 0.83 \\
\hline Total & 37 & 97 & 105 & 0.78 & 0.82 & $\mathbf{0}$ & $\mathbf{0}$ & 0.78 & 0.82 \\
\hline \multicolumn{10}{|l|}{ Reuler } \\
\hline 2003 & - & - & - & - & - & - & - & - & - \\
\hline 27 May to 5 July 2004 & 10 & 45 & 32 & 0.70 & 0.70 & 0 & 0 & 0.70 & 0.70 \\
\hline 16 May to 11 July 2005 & 11 & 24 & 23 & 0.82 & 1.00 & 0 & 0 & 0.82 & 1.00 \\
\hline Total & 21 & 69 & 55 & 0.76 & 0.85 & $\mathbf{0}$ & $\mathbf{0}$ & 0.76 & 0.85 \\
\hline All & 148 & 433 & 413 & 0.79 & 0.84 & 0.01 & 0.02 & 0.77 & 0.83 \\
\hline
\end{tabular}

${ }^{a}$ Average for each field site over three cropping seasons indicated in bold; - indicates no data.

${ }^{b}$ Duration of infection period $=$ total number of hours with a high probability of infection simulated by PROCULTURE.

${ }^{c}$ Probability of detection (POD) of M. graminicola infection is the number of cases where infections are both simulated and observed against the number of infections observed. Perfect forecast $=1$.

${ }^{\mathrm{d}}$ False alarm ration (FAR) of M. graminicola infection is the number of observed infections not simulated against the number of infections observed in the field. Perfect forecast $=0$.

${ }^{\text {e }}$ Critical success index (CSI) of M. graminicola infection takes into account both false alarms and missed events. POD ${ }_{\mathrm{so}}, \mathrm{FAR}_{\mathrm{so}}$, and $\mathrm{CSI}_{\mathrm{so}} \mathrm{show}$ the infection occurrence comparison between infection periods (on the last three leaves) determined by visual observations and simulated by the PROCULTURE model using measurements from four rain-gauges and weather-radar estimates. Perfect value $=1$.

${ }^{\mathrm{f}}$ Field sites and observation period; the Humain site is in Belgium and the Useldange, Burmerange, and Reuler sites are in Luxembourg.

g Number of infection events deduced from visually observed symptoms in the field sites on the upper three leaves. 
covered by the instrument, the use of radar could be a beneficial alternative for site-specific SLB risk assessment.

Efforts are now being made to introduce weather-radar data as the input for the PROCULTURE simulation model. The results from this study could help to improve the existing warning system in Belgium and Luxembourg by taking into account both sources of rainfall measurements. An enhanced spatial representation of precipitation will inevitably improve the current warning systems.

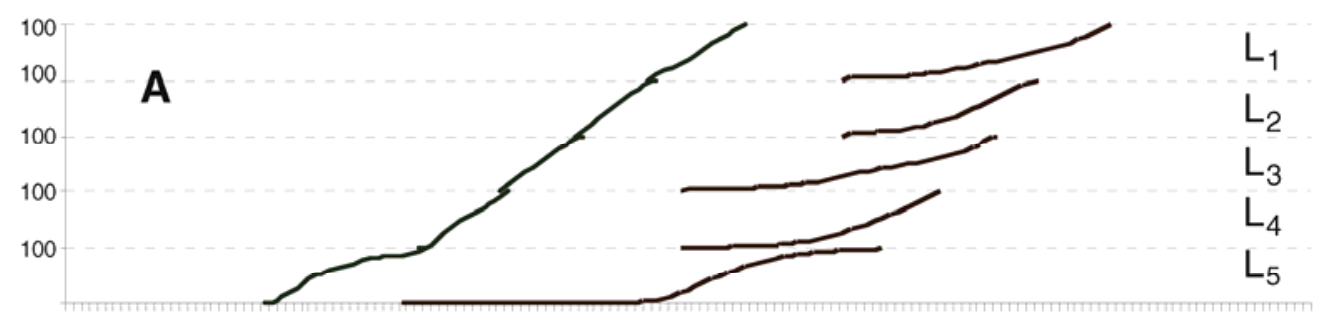

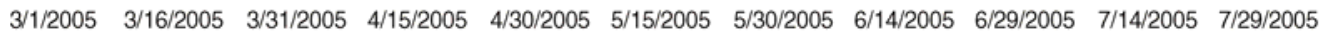

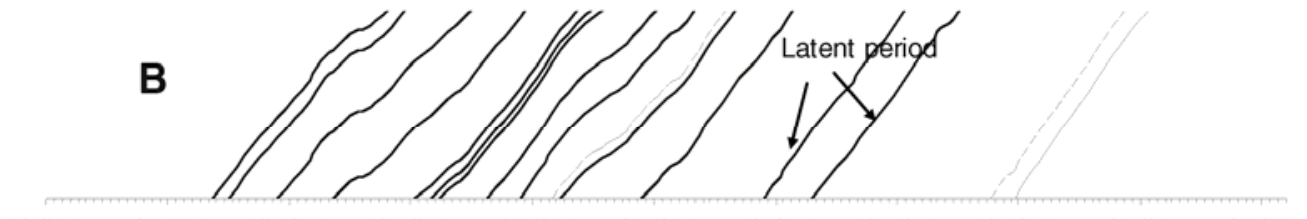

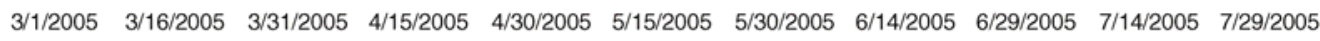
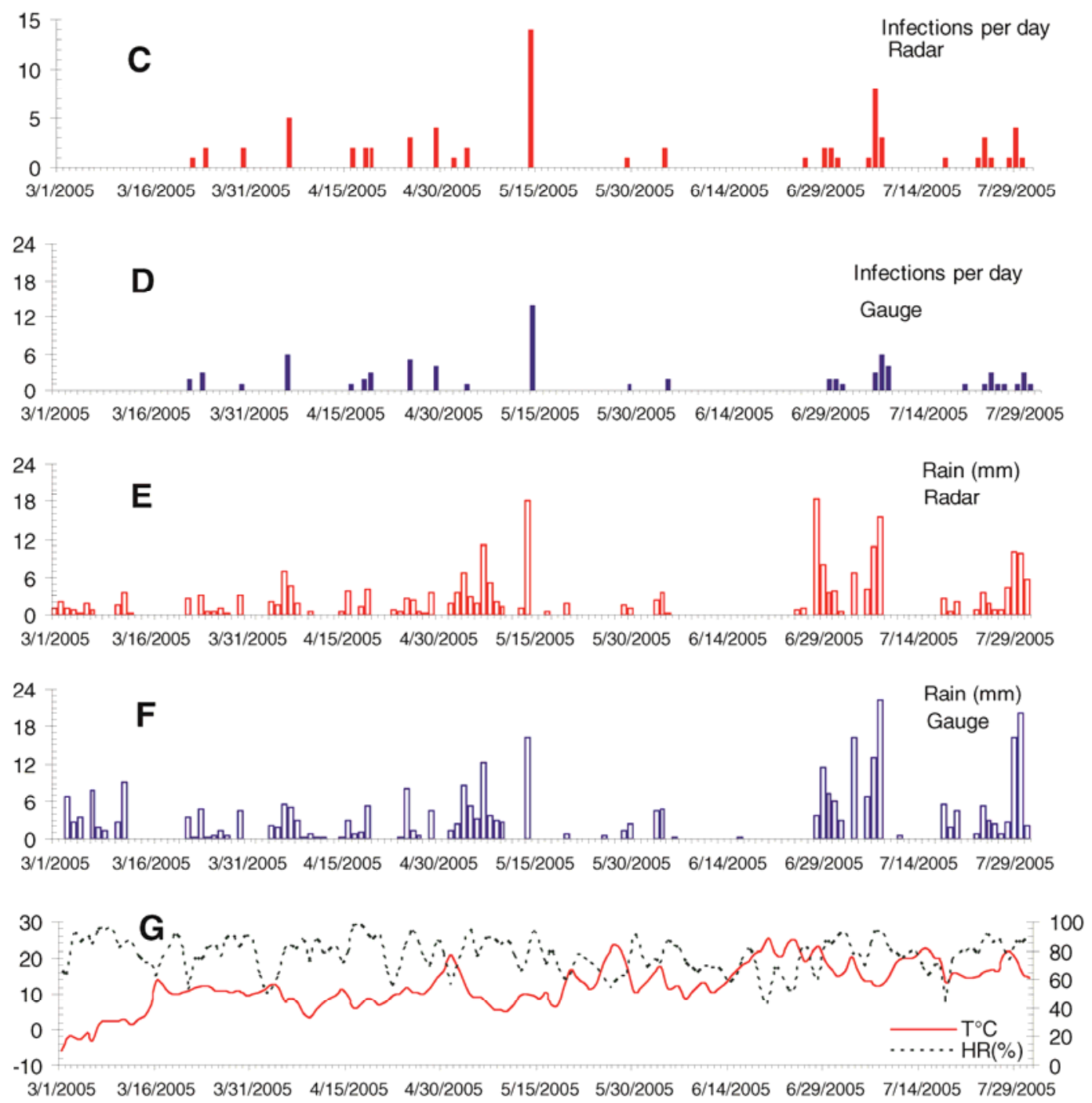

Fig. 4. Example of inputs and outputs of the Septoria leaf blotch (SLB) risk assessment model PROCULTURE in winter wheat fields at the Humain site in 2005. A, Green lines represent the percentage of leaf area development for leaves L5 to L1. Pink lines represent SLB severity (\%) on L5 to L1. B, Latent period and duration (dashed line indicates the latent period caused only by radar rainfall data). C, Number of hours per day with a high probability of infection determined by using radar rainfall estimate data. D, Number of hours per day with a high probability of infection determined by using rain-gauge precipitation data. E, Royal Meteorological Institute of Belgium radar daily rainfall estimates from the Humain weather station. F, Daily rain-gauge precipitation $(\mathrm{mm})$ measured at the Humain weather station. $\mathbf{G}$, Average daily air temperature $\left({ }^{\circ} \mathrm{C}\right)$ and relative humidity $(\%)$. 
Consequently, they could help target appropriate fungicide applications. In the medium term, if the results are confirmed for a larger precipitation dataset and across more stations, the sole use of radar data in the disease-warning system should be considered. Results from this study also encourage research on additional radar technology applications for various crops. Similarly, areas with a significant incidence of $M$. graminicola but with a low spatial density of rain gauges would benefit greatly from such a forecasting system.

\section{Acknowledgments}

The research work reported in this article was supported by the Ministry for Culture, Higher Education and Scientific Research in Luxembourg. We thank the Ministère de la Région Wallonne, Direction Générale de l'Agriculture for grants for the development of the PROCULTURE model made available for this study by the Plant Pathology Unit of Université catholique de Louvain; the Hydrological Service of the Walloon Region of Belgium and the Administration des Services Techniques de l'Agriculture in Luxembourg for providing the rain-gauge data used in this study; L. Hubert for providing critical comments on the manuscript; and G. Reiland, M. Kails, M. Bertrand, and V. Shyns for their technical support.

\section{Literature Cited}

1. Anonymous. 1986. Winter Wheat Managed Disease Control. Ministry of Agriculture Fisheries \& Food, Advisory Leaflet No. P831. London.

2. Berne, A., ten Heggeler, M., Uijlenhoet, R., Delobbe, L., Dierickx, P., and de Wit, M. 2005. A preliminary investigation of radar rainfall estimation in the Ardennes region and a first hydrological application for the Ourthe catchment. Nat. Hazard. Earth Syst. 5:267-274.

3. Calay, F., Coquillart, L., Lucas, C., Lemaire, D., Bodson, B., Moreau, J. M., and Maraite, H. 2002. Lessons from year 2001 Mycosphaerella graminicola epidemic on winter wheat in Belgium. Wet. Abstr. 54th Int. Symp. Crop Prot. Meded. Fac. Landbouwwet. Rijksuniv. Gent 67/2:197-204.

4. Chen, R. S., and McDonald, B. A. 1996. Sexual reproduction plays a major role in the genetic structure of populations of the fungus Mycosphaerella graminicola. Genetics 142:1119-1127.

5. Cicogna, A., Dietrich, S., Gani, M., Giovanardi, R., and Sandra, M. 2005. Use of meteorological radar to estimate leaf wetness as data input for application of territorial epidemiological model (downy mildew-Plasmopara viticola). Phys. Chem. Earth 30:201-207.

6. Colle, B. A., Westrick, K. J., and Mass, C. F. 1999. Evaluation of MM5 and Eta-10 precipitation forecasts over the Pacific Northwest during the cool season. Weather Forecast. 14:137-154

7. Delobbe, L., Dehem, D., Dierickx, P., Roulin, E., Thunus, M., and Tricot, C. 2006. Combined use of radar and gauge observations for hydrological applications in the Walloon region of Belgium. Fourth European Conference on Radar in Meteorology and Hydrology, Barcelona, Spain.

8. Einfalt, T., Nielsen, A. K., Golz, C., Jensen, N. E., Quirmbach, M., Vaes, G., and Vieux, B. 2004. Towards a roadmap for use of radar rainfall data in urban drainage. J. Hydrol. 299:186-202.

9. El Jarroudi, M. 2005. Evaluation des paramètres épidémiologiques des principales maladies cryptogamiques affectant les feuilles du blé d'hiver au Grand-Duché de Luxembourg: Calibration et validation d'un modèle de prévision. Ph.D. thesis, Université de Liège, Arlon.

10. El Jarroudi, M., Delfosse, P., Maraite, H., Hoffmann, L., and Tychon, B. 2009. Assessing the accuracy of simulation model for Septoria leaf blotch disease progress on winter wheat. Plant Dis. 93:983-992.

11. Eriksen, L., Shaw, M. W., and Ostergard, H. 2001. A model of the effect of pseudothecia on genetic recombination and epidemic development in populations of Mycosphaerella graminicola. Phytopathology 91:240-248.

12. Gladders, P., Paveley, N. D., Barrie, I. A., Hardwick, N. V., Hims, M. J., Langton, S., and Taylor, M. C. 2001. Agronomic and meteorological factors affecting the severity of leaf blotch caused by Mycosphaerella graminicola in commercial wheat crops in England. Ann. Appl. Biol. 138:301-311.

13. Goudenhoofdt, E., and Delobbe, L. 2009. Evaluation of radar-gauge merging methods for quantitative precipitation estimates. Hydrol. Earth Syst. Sci. 13:195-203

14. Hagan, A. K., Bowen, K. L., Bauske, E. M., Getz, R. R., and Adams, S. D. 1999. Doppler radar precipitation estimates added to AU-Pnut advisory. (Abstr.) Phytopathology 89:S32.

15. Hansen, J. G., Secher, B. J. N., Jorgensen, L. N., and Welling, B. 1994. Thresholds for control of Septoria spp. in winter wheat based on precipitation and growth stage. Plant Pathol. 43:183-189.

16. Hatfield, J. L., Prueger, J. H., and Meek, D. W. 1999. Spatial variation of rainfall over a large watershed in central Iowa. Theor. Appl. Climatol. 64:49-60.

17. Henze, M., Beyer, M., Klink, H., and Verreet, J.-A. 2007. Characterizing meteorological scenarios favorable for Septoria tritici infections in wheat and estimation of ILatent periods. Plant Dis. 91:1445-1449.

18. Hubbard, K. G. 1994. Spatial variability of daily weather variables in the high-plains of the USA. Agric. For. Meteorol. 68:29-41.

19. Huber, L., and Gillespie, T. J. 1992. Modeling leaf wetness in relation to plant-disease epidemiology. Annu. Rev. Phytopathol. 30:553-577.

20. Hunter, T., Coker, R. R., and Royle, D. J. 1999. The teleomorph stage, Mycosphaerella graminicola, in epidemics of Septoria tritici blotch on winter wheat in the UK. Plant Pathol. 48:51-57.

21. James, C. A. 1971. Manual of assessment keys for plant diseases. Canada Department of Agriculture, Publ. No.1458. American Phytopathological Society, St. Paul, MN.

22. Junk, J., Görgen, K., El Jarroudi, M., Delfosse, P., Pfister, L., and Hoffmann, L. 2008. Operational application and improvements of the disease risk forecast model PROCULTURE to optimize fungicides spray for the Septoria leaf blotch disease in winter wheat in Luxembourg. Adv. Sci. Res. 2:57-60.

23. Kema, G. H. J., and Silfhout, C. H. 1996. Histology of the pathogenesis of Mycosphaerella graminicola in wheat. Phytopathology 86:777-786.

24. Kemerait, R. C., Brenneman, T. B., and Hoogenboom, G. 2003. Evaluation of Doppler-radar based AU-Pnut advisory for disease management in peanut. (Abstr.) Phytopathology 93:S44

25. Krajewski, W. F., Ciach, G. J., and Habib, E. 2003. An analysis of smallscale rainfall variability in different climatic regimes. Hydrol. Sci. J. 48:151-162.

26. Lemaire, E. D., Amand, O., and Maraite, H. 2003. Evolution of PROCULTURE, a disease risk simulation model for decision taking in Mycosphaerella graminicola control. Pages 83 to 90 in: Global Insights into the Septoria and Stagonospora Diseases of Cereals. Proc. 6th Int. Symp. Septoria and Stagonospora Dis. Cereals. G. H. J. Kema, M. Van Ginkel, and M. Harrabi, eds.. Tunis, Tunisia.

27. Lovell, D. J., Parker, S. R., Hunter, T., Royle, D. J., and Coker, R. R. 1997. Influence of crop growth and structure on the risk of epidemics by $M y$ cosphaerella graminicola (Septoria tritici) in winter wheat. Plant Pathol. 46:126-138.

28. Marshall, J. S., and Palmer, M. W. 1948. The distribution of rain drops with size. J. Meteorol. 5:165-166.

29. Moreau, J. M., and Maraite, H. 1999. Integration of knowledge on wheat phenology and Septoria tritici epidemiology into a disease risk simulation model validated in Belgium. Asp. Appl. Biol. 55:1-6.

30. Moreau, J. M., and Maraite, H. 2000. Development of an interaction decision-support system on a web site for control of Mycosphaerella graminicola in winter wheat. Bull. OEPV/EPPO Bull. 30:161-163.

31. Pietravalle, S., Shaw, M. W., Parker, S. R., and Van den Bosch, F. 2003. Modeling of relationships between weather and Septoria tritici epidemics on winter wheat: a critical approach. Phytopathology 93:1329-1339.

32. Royle, D. J., Lovell, D. J., Coakley, S. M., and Shaner, G. 1993. Predicting the effects of climate change on Septoria tritici on winter wheat. In: Abstr. 6th Int. Congr. Plant Pathol. Montreal.

33. Shaner, G., and Finney, R. 1976. Weather and epidemics of Septoria leaf blotch of wheat. Phytopathology 66:781-785.

34. Shaw, M. W. 1990. Effects of temperature, leaf wetness and cultivar on the latent period on Mycosphaerella graminicola on winter wheat. Plant Pathol. $39: 255-268$.

35. Shaw, M. W., and Royle, D. J. 1989. Estimation and validation of function describing the rate at which Mycosphaerella graminicola causes yield loss in winter wheat. Ann. Appl. Biol. 115:425-442.

36. Shaw, M. W., and Royle, D. J. 1993. Factors determining the severity of epidemics of Mycosphaerella graminicola (Septoria tritici) on winter wheat in the U.K. Plant Pathol. 42:882-899.

37. Thomas, M. R., Cook, R. J., and King, J. E. 1989. Factors affecting development of Septoria tritici in winter wheat and its affect on yield. Plant Pathol. 38:246-257.

38. Tomerlin, J. R., and Howell, A. 1988. Distrain: a computer program for training people to estimate disease severity on cereal leaves. Plant Dis. 72:455-459.

39. Tyldesley, J. B., and Thompson, N. 1980. Forecasting Septoria nodorum on winter wheat in England and Wales. Plant Pathol. 29:9-20.

40. Wilks, D. S. 1995. Statistical Methods in the Atmospheric Sciences. Academic Press, San Diego, CA.

41. Workneh, F., Narasimhan, B., Srinivasan, R., and Rush, C. A. 2005. Potential of radar-estimated rainfall for plant disease risk forecast. Phytopathology 95:25-27.

42. Workneh, F., Narasimhan, B., Srinivasan, R., and Rush, C. M. 2006. Assessment of regional site-specific sorghum ergot severity potential using radarrainfall measurement. Plant Dis. 90:704-707.

43. Zadoks, J. C., Chang, T. T., and Konzak, C. F. 1974. A decimal code for the growth stages of cereals. Weed Res. 14:415-421. 